\title{
Torsional Coupling in Sliding Base-Isolated Structures
}

\author{
By Satish Nagarajaiah, ${ }^{1}$ Associate Member, ASCE, Andrei M. Reinhorn, ${ }^{2}$ \\ Member, ASCE, and Michalakis C. Constantinou, ${ }^{3}$ \\ Associate Member, ASCE
}

\begin{abstract}
The lateral-torsional response of base-isolated structures, with sliding isolation system due to bidirectional lateral ground motion, is studied. The objective of the study is to identify the key system parameters that lead to significant torsional coupling in sliding base-isolated structures. The analysis procedure adopted can capture the highly nonlinear behavior of sliding systems in plane motion. The nonlinear biaxial stick-slip characteristics of sliding bearings and the velocity dependence of coefficient of friction are accounted for. The study considers multistoried structures with variable number of bearings subjected to the effects of earthquakes with various frequency content and different peak ground accelerations. It is shown that, although the total superstructure response is reduced significantly due to the effects of sliding base isolation, torsional coupling can be significant depending on the superstructure eccentricity and the lateral-torsional flexibility of the superstructure and the base.
\end{abstract}

\section{INTRODUCTION}

Sliding isolation systems consist of a combination of: (1) Sliding bearings that support the superstructure and limit the lateral force entering the superstructure; and (2) springs or other recentering devices that provide the recentering force to limit the permanent lateral displacements. Coupled lateral-torsional motions occur in sliding isolated structures, when subjected to lateral ground motion, if an eccentricity exists between the center of stiffness (CS) and the center of mass (CM) of the superstructure. Torsional coupling is, however, negligible in sliding isolated structures in the absence of superstructure eccentricity even if such an eccentricity is present in the sliding isolation system. In base-isolated structures with elastomeric isolation systems, torsional motions occur due to eccentricity in the isolation system (Pan and Kelly 1983; Lee 1980; Eisenberger and Rutenberg 1986; Buckle and Mayes 1990).

Zayas et al. (1987) have studied the torsional response of sliding isolated structures by means of shake table tests. The main conclusion of their study was that the torsional response is negligible in sliding isolated structures even in the presence of large mass and stiffness eccentricities, when compared to the torsional response of nonisolated structures (Goel and Chopra 1990; Hart et al. 1975; Sadek and Tso 1988; Pekau and Guimond 1991; Reinhorn, Rutenberg and Gluck 1977; Reinhorn 1980). However, the conclusions of the aforementioned experimental study were limited to the structural models tested experimentally.

Lateral response of sliding isolated structures, without considering the

\footnotetext{
${ }^{1}$ Res. Asst. Prof., Dept. of Civ. Engrg., State Univ. of New York, Buffalo, NY 14260 .

${ }^{2}$ Prof., Dept. of Civ. Engrg., State Univ. of New York, Buffalo, NY.

${ }^{3}$ Assoc. Prof., Dept. of Civ. Engrg., State Univ. of New York, Buffalo, NY.

Note. Discussion open until June 1, 1993. To extend the closing date one month, a written request must be filed with the ASCE Manager of Journals. The manuscript for this paper was submitted for review and possible publication on January 8, 1992. This paper is part of the Journal of Structural Engineering, Vol. 119, No. 1, January, 1993. CASCE, ISSN 0733-9445/93/0001-0130/\$1.00 + \$.15 per page. Paper No. 3105 .
} 
torsional coupling, has been the subject of detailed study by several investigators (Constantinou, Mokha and Reinhorn 1991; Su et al. 1989; Mostaghel and Khodaverdian 1988). However, there are very few studies on coupled lateral-torsional response of sliding isolated structures. One notable study by Zayas et al. (1989) analyzes structural models similar to those tested previously by Zayas et al. (1987). The conclusion of this study was that the torsional response is virtually negligible in sliding isolated structures and in the worst cases of eccentricities (i.e., superstructure eccentricity of $45 \%$ the length of the structure) the torsional motions add $5 \%$ to the lateral motions at the CM.

In the study by Zayas et al. (1989) the sliding bearings were modeled by two elastoplastic springs in the lateral $x$ - and $y$-directions. Such a representation of sliding bearings neglects two important effects: (1) Biaxial interaction between lateral forces in the two orthogonal directions; and (2) the velocity dependence of the coefficient of friction. Furthermore, the ratio of lateral to torsional isolation period considered was nearly 2 . The ratio of lateral to torsional superstructure period was also nearly 2 . This resulted in a torsionally stiff system with small or negligible torsional motions even in cases with large stiffness eccentricity in the superstructure. Hence the conclusion of the studies by Zayas et al. (1987, 1989), that torsional motions are negligible in sliding isolated structures, is not applicable in general and is applicable to torsionally stiff sliding isolated structures only. It is evident from this brief review of earlier work that conclusions of these studies are not valid in general, but are restricted to the particular system considered and the underlying modeling assumptions. Hence there is a need for a more comprehensive investigation.

The objective of this study is to identify the key parameters that significantly influence the torsional coupling in base-isolated structures with elastic superstructure and nonlinear sliding isolation system. Furthermore, the effect of earthquakes with various frequency content and different peak ground accelerations are studied. Influences of the following parameters are investigated: (1) The flexibility of the superstructure; (2) the ratio of uncoupled torsional to lateral frequencies; (3) the stiffness eccentricity in the superstructure; (4) the eccentricity in the isolation system; (5) the higher mode effects; and (6) the effect of number of bearings and the plan dimensions of the structure.

The study in this paper considers a wide variety of sliding isolation systems used in conjunction with a variety of structural systems. Special considerations are given to following aspects: (1) Sliding isolation systems with weak restoring or recentering springs; (2) torsionally flexible superstructure and isolation system with torsional to lateral frequency ratio varying from 0.8 to 2.0; and (3) nonlinear biaxial stick-slip characteristics of sliding bearings and velocity dependence of the coefficient of friction. It is shown that the torsional flexibility has important influences on the torsional response. It is further shown that in torsionally stiff systems mentioned, the torsional motion is small or negligible.

\section{Analysis Procedure and Analytical Model}

The dynamic analysis for the study reported in this paper was carried out using a new computer model 3D-BASIS (Nagarajaiah et al. 1991a, 1991b) developed specifically for nonlinear dynamic analysis of asymmetric plan multistory base isolated structures [asymmetric plan shown in Fig. 1(a)] with elastomeric and/or sliding isolation systems. Sliding systems are usually made 

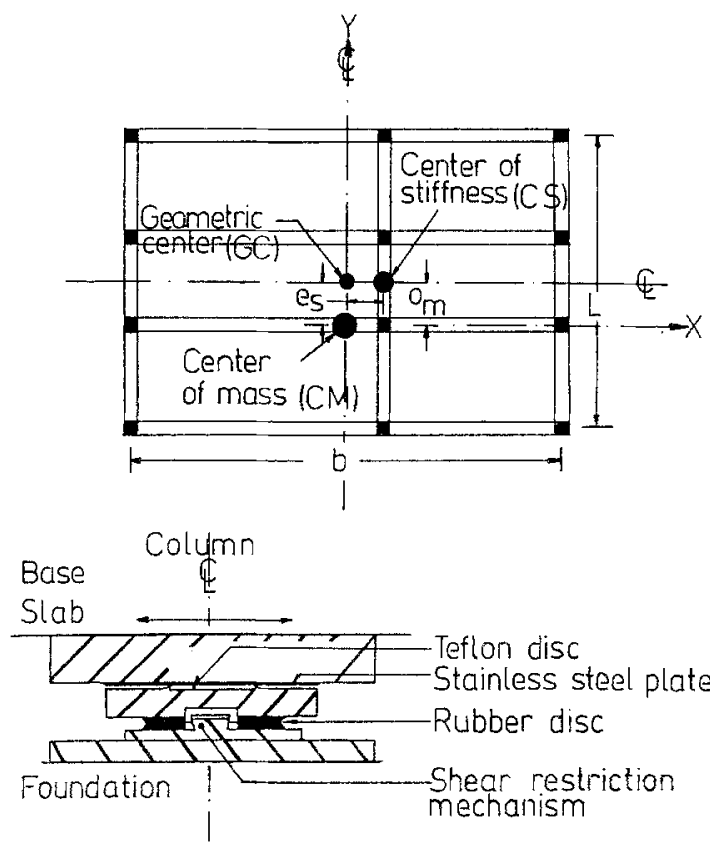

(b)
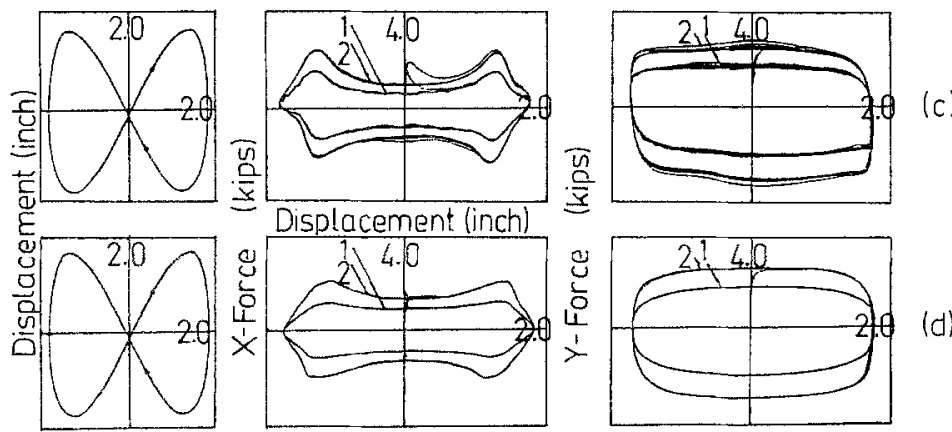

(d)

FIG. 1. Structura! System and Sliding Bearing Considered: (a) Floor Plan of Multistory Structure; (b) Section of Teflon Disc Sliding Bearing; (c) Measured Biaxial Force-Displacement Response of Sliding Bearing; (d) Simulated Biaxial ForceDisplacement Response of Sliding Bearing

of Teflon-steel sliding bearings and recentering springs. Fig. 1(b) shows a cross section of a Teflon-steel sliding bearing located concentrically under each column and between the base slab and the foundation. A brief description of the analytical model for Teflon sliding bearings and its validity, and also the validity of the analytical model and solution algorithm in 3DBASIS are presented in the following sections.

\section{Biaxial Model for Sliding Bearings in 3D-BASIS}

For a sliding bearing, the mobilized forces can be described by the following equations (Constantinou et al. 1990): 


$$
\begin{aligned}
& F_{x}=\mu_{s} N Z_{x} \\
& F_{y}=\mu_{s} N Z_{y}
\end{aligned}
$$

in which $N=$ the vertical load on the bearing and $\mu_{s}=$ the coefficient of friction.

Based on experimental results, the coefficient of sliding friction is assumed to follow the relation:

$$
\mu_{s}=f_{\max }-\Delta f \cdot \exp \left(-a \mid \dot{U}^{*}\right)
$$

in which $f_{\max }=$ maximum value of the coefficient of friction and $\Delta f=$ difference between the maximum and minimum (at $\dot{U}^{*} \sim 0$ ) values of the coefficient of friction. The friction coefficient is dependent mainly on: (1) The bearing pressure; and (2) the instantaneous velocity of sliding (Constantinou et al. 1990; Mokha et al. 1990; Campbell et al. 1991). The instantaneous velocity, $\dot{U}^{*}$, is defined as:

$$
\dot{U}^{*}=\left(\dot{U}_{x}^{* 2}+\dot{U}_{y}^{* 2}\right)^{1 / 2}
$$

where $\dot{U}_{x}^{*}$ and $\dot{U}_{y}^{*}=$ velocities at the bearing in the $x$ - and $y$-directions. In addition, in (1) and (2) the functions $Z_{x}$ and $Z_{y}$ (which are bounded by the values \pm 1 ) account for the direction and the biaxial interaction of frictional forces, and also account for the conditions of seperation and reattachment (instead of a signum function). Furthermore, $Z_{x}$ and $Z_{y}=$ hysteretic dimensionless quantities that are governed by the following coupled differential equations (Park et al. 1986):

$$
\begin{aligned}
& \left\{\begin{array}{l}
\dot{Z}_{x} Y \\
\dot{Z}_{y} Y
\end{array}\right\}=\left\{\begin{array}{c}
A \dot{U}_{x}^{*} \\
A \dot{U}_{y}^{*}
\end{array}\right\} \\
& -\left[\begin{array}{cc}
Z_{x}^{2}\left(\gamma \operatorname{sgn}\left(\dot{U}_{x}^{*} Z_{x}\right)+\beta\right) & Z_{x} Z_{y}\left(\gamma \operatorname{sgn}\left(\dot{U}_{y}^{*} Z_{y}\right)+\beta\right) \\
Z_{x} Z_{y}\left(\gamma \operatorname{sgn}\left(\dot{U}_{x}^{*} Z_{x}\right)+\beta\right) & Z_{y}^{2}\left(\gamma \operatorname{sgn}\left(U_{y}^{*} Z_{y}\right)+\beta\right)
\end{array}\right]\left\{\begin{array}{c}
\dot{U}_{x}^{*} \\
\dot{U}_{y}^{*}
\end{array}\right\}
\end{aligned}
$$

in which $y=$ "yield" displacement characterizing the shear displacement of Teflon before sliding commences, and $A, \beta, \gamma=$ dimensionless quantities. The values of $A=1, \beta=0.1, \gamma=0.9$, and $y=0.254 \mathrm{~mm}(0.01 \mathrm{in}$.) are used in this paper. Solution of (5) along with (1)-(4) enables determination of the forces in each sliding bearing. This model provides the basis for friction analysis. The validity of this model is verified in the following section.

\section{Validity of Biaxial Model for Sliding Bearings in 3D-BASIS}

The validity of the biaxial model just presented is verified by comparison with the experimental results of tests on Teflon-steel sliding bearings under simultaneous compression and high-velocity bidirectional motion (Mokha et al. 1993). In the tests the sliding interface was made up of two 127-mm (5-in.) diameter unfilled Teflon disc specimens and polished stainless steel plates. The bearing pressure, at which the tests were conducted, was 3.45 $\mathrm{MPa}(500 \mathrm{psi})$. Values of the parameters in (3) varied in the range $f_{\max }=$ $0.12-0.14, \Delta f=0.0811-0.094$, and $a=15.75-17.72 \mathrm{~s} / \mathrm{m} .(0.4-0.45 \mathrm{sec} /$ in.). The experimental program included several patterns of out-of-phase bidirectional motions, one of which was an eight-shaped motion. The results of this eight-shaped motion are considered for comparison herein.

The imposed bidirectional motion is shown in Fig. $1(c)$ and $1(d)$, and is given by: 


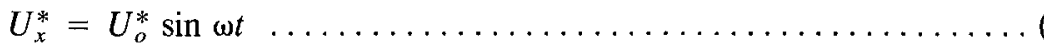

$U_{y}^{*}=U_{0}^{*} \sin 2 \omega t$

in which, $U_{o}^{*}=45.466 \mathrm{~mm}(1.79 \mathrm{in}$.$) , and \omega=0.5 \mathrm{rad} / \mathrm{s}$ for test 1 , and $\omega=2.22 \mathrm{rad} / \mathrm{s}$ for test 2 . The experimental and simulated results for tests 1 and 2 shown in Figs. 1(c) and 1(d), respectively, indicate good agreement. Note the significant interaction between the forces in the $x$ - and $y$-directions. If the biaxial interaction was neglected the shape of both $x$ - and $y$-direction force-displacement loops would be similar to the $y$-direction loops shown in Figs. 1 $(c)$ and Fig. 1 $(d)$ or similar to uniaxial loops. In the loops of tests 1 and 2 velocity dependence of the coefficient of friction can be observed. Test 1 is at a lower velocity and hence the maximum friction force is smaller than that in test 2 , in which the sliding velocity is higher. If the velocity dependence of the coefficient of friction was neglected the loops would be rigid-plastic. Furthermore, the effect of biaxial interaction in sliding bearings, as just evidenced, on the response of sliding isolated structures is important (Nagarajaiah et al. 1990; Mokha et al. 1993).

\section{Validity of Analytical Model and Solution Algorithm in 3D-BASIS}

The validity of the analytical model and solution algorithm has been demonstrated by comparison with experimental results from unidirectional shake table tests on sliding isolated multistoried structures (Nagarajaiah et al. 1991a, 1991b). The validity of the analytical model and solution algorithm used in 3D-BASIS is demostrated further herein by comparison with experimental results from bidirectional shake table tests on a sliding isolated model by Hisano et al. (1988). The tested model was a one-eighth-scale steel structure, 3,048-mm (120-in.) long and 2,286-mm (90-in.) wide, on a sliding isolation system consisting of nine sliding bearings with four rubber springs. The model weighed $101 \mathrm{kN}$ (10.1 tons), with $80.5 \mathrm{kN}$ (8.05 tons) of superstructure weight and $20.5 \mathrm{kN}$ (2.05 tons) of base weight. The radius of gyration was $r=0.29 \mathrm{~L}$. The model had symmetric stiffness and mass properties. For the scaled superstructure the uncoupled lateral period was $0.11 \mathrm{~s}$ (corresponding to $0.3 \mathrm{~s}$ in prototype) and the uncoupled torsional period was $0.07 \mathrm{~s}(0.2 \mathrm{~s}$ in prototype). The damping ratio measured in the superstructure was $1 \%$. For the isolation system the uncoupled lateral period was $0.35 \mathrm{~s}(1.0 \mathrm{~s}$ in prototype $)$ and the uncoupled torsional period was 0.208 $\mathrm{s}(0.588 \mathrm{~s}$ in prototype). The diameter of the sliding bearings were between $69.85 \mathrm{~mm}$ ( $2.75 \mathrm{in}$.) and $35.56 \mathrm{~mm}$ (1.4 in.). The maximum bearing pressure during tests was $6.21 \mathrm{MPa}(900 \mathrm{psi})$. The friction, characterized by (3) was measured with the following coefficients: $f_{\max }=0.15$; and $\Delta f=0.05$. The model structure was excited by time scaled accelerations of 1940 El Centro NS and EW components. The peak table acceleration in both the directions was scaled up by a factor of 1.5. Fig. 2 shows the measured and simulated frame acceleration and the base displacement in the NS direction, and the displacement orbit of the CM of the base. The historical accelerogram of $1940 \mathrm{El}$ Centro motion scaled appropriately was used as the excitation for the analytical simulation, as the achieved shake table acceleration time history was not available. Despite this a comparison between the measured and simulated results show good agreement, including major features of the displacement orbit.

From the comparison with experimental biaxial force-displacement loops and the comparison with bidirectional shake table test results it is evident 

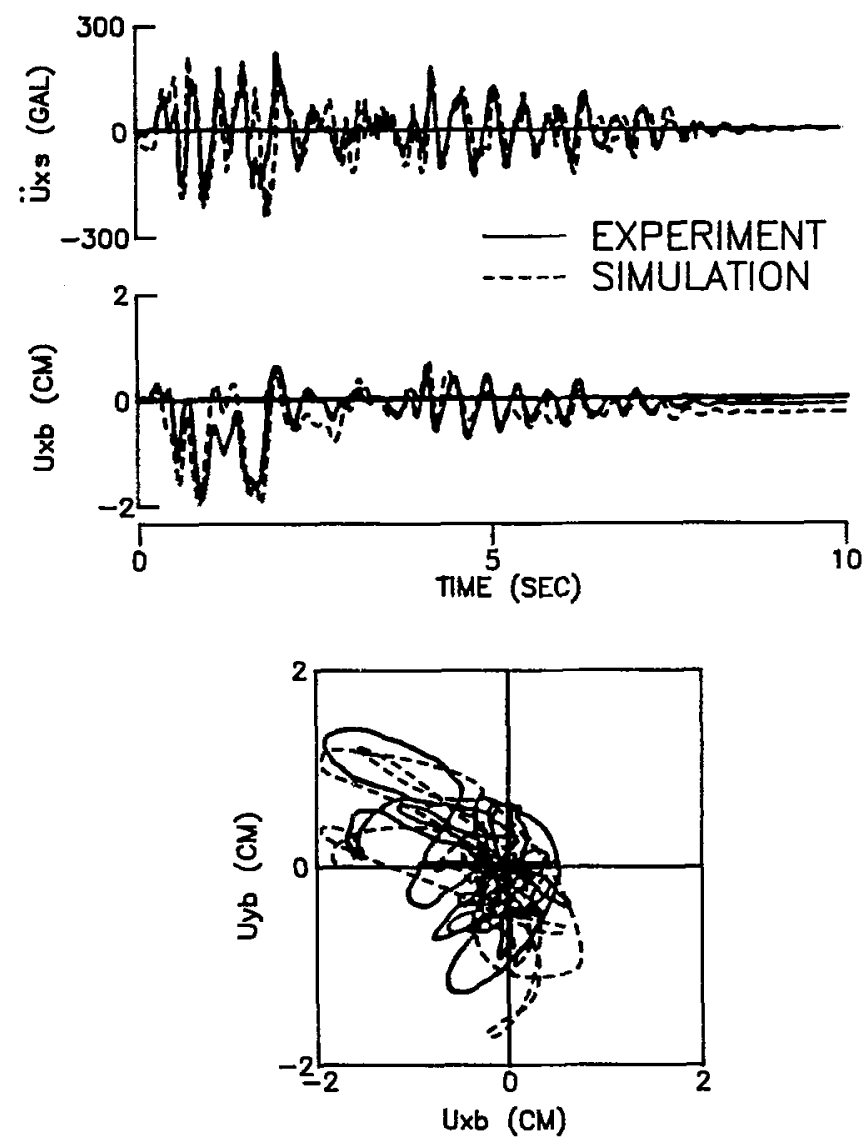

FIG. 2. Comparison of Simulated (3D-BASIS) and Measured Results of Bidirectional Shake Table Tests with El Centro Excitation

that the analytical model and solution algorithm in 3D-BASIS can provide the analysis capability necessary for this study.

\section{Torsionally Coupled System}

In this study, a series of multistoried 3-D-shear buildings are considered and are assumed to be elastic while the isolation systems exhibit nonlinear behavior. Three master degrees of freedom, two translational and one torsional degree of freedom, attached to the $\mathrm{CM}$ of the floors and the base are considered. The $\mathrm{CM}$ of all the floors and the base are assumed to be on the same vertical axis, which is also the reference axis. The asymmetric floor plan shown in Fig. 1(a) is identical for all the floors. The floors and the base are assumed to be rigid. The sliding isolation system is considered to be located between the base slab and the foundation.

When a mass offset is considered, the entire vertical axis of the CM of the floors and the base is assumed to be offset with respect to the geometric center (GC) of the building [see Fig. 1(a)]. Henceforth, such an offset is referred to as "mass offset" denoted by $o_{m}$. The stiffness eccentricity in the 
superstructure, $e_{s}$, represents the distance measured from the vertical axis of the CM to the vertical axis of the CS [see Fig. 1(a)].

The strength distribution in the isolation system is represented by the center of strength (CYS) (Goel and Chopra 1990; Eisenberger and Rutenberg 1986; Sadek and Tso 1988). The CYS is defined as the location of the resultant of maximum frictional forces at the bearings (assuming that the maximum coefficient of friction, of the velocity dependent friction model, will be mobilized). A strength eccentricity is defined as the distance between the CM of the base and the CYS of the isolation system, and is denoted by $e_{b}$. The frictional forces at the bearings depend on the mass/weight distribution. In this study, for the sake of simplicity, mass offset is considered only in the $y$-direction [see Fig. 1(a)], and no strength eccentricity and mass offset are considered in the $x$-direction. The strength eccentricity, $e_{b}$, due to the mass offset in the $y$-direction is defined as follows:

$e_{b}=\frac{1}{F_{x}^{f}} \sum_{j} y_{j} f_{x j}^{f}$

where $F_{x}^{f}=$ the resultant of maximum frictional forces at bearings in the $x$-direction, and $f_{x j}^{f}=$ the maximum frictional force at the $j$ th bearing in the $x$-direction, and $y_{j}=$ distance of the $j$ th bearing from the CM of the base in the $y$-direction.

The uncoupled fundamental lateral periods of the superstructure in fixed base condition (i.e., preisolation periods) in the $x$-and $y$-directions are considered to be identical throughout the study and are designated by $T_{s}$ with the corresponding circular frequencies by $\omega_{s}$. The uncoupled fundamental torsional frequency is designated by $\omega_{\theta s}$. The lateral and the torsional frequencies, $\omega_{s}$ and $\omega_{\theta s}$, for a single story structure (one of the cases in this paper) are defined as follows:

$\omega_{s}=\sqrt{\frac{K_{s}}{m}}$

$\omega_{\theta s}=\sqrt{\frac{K_{\theta s}}{m r^{2}}}$

where $K_{s}=$ lateral stiffness in the $x$ - or $y$-direction and $K_{\theta s}=$ torsional stiffness about the CM (i.e., at the CS of an equivalent uncoupled system with $e_{s} / r=0$ ), of the fixed base superstructure, $m=$ mass of the superstructure and $r=$ radius of gyration of the floor about the $\mathrm{CM}$. The ratio of torsional-to-lateral frequencies is defined as follows:

$\Omega_{\theta s}=\frac{\omega_{\theta s}}{\omega_{s}}$

In the present study, a sliding isolation system consisting of sliding bearings and restoring or recentering linear springs is considered. This system is representative of most sliding systems used in practice (Constantinou et al. 1991; Mostaghel et al. 1988; Zayas et al. 1987; Hisano et al. 1988). It is assumed that the springs are built-in along with the slider, i.e., virtually concentric with the sliding bearing. The uncoupled lateral periods of the isolation system, calculated considering only the restoring spring stiffnesses, neglecting the frictional forces and assuming the superstructure to be rigid, are considered to be identical in both $x$ - and $y$-directions throughout the 
study. These periods will be designated by $T_{b}$ and the corresponding frequencies by $\omega_{b}$. The uncoupled torsional frequency of the base is designated by $\omega_{\theta b}$. The lateral frequency, $\omega_{b}$, the torsional frequency, $\omega_{\theta b}$, and the ratio of torsional to lateral frequencies of the base, $\Omega_{\theta b}$, are defined in an analogous manner as $\omega_{s}, \omega_{\theta s}$, and $\Omega_{\theta s}$, considering only the stiffness of the restoring springs and neglecting the frictional forces. The variations in torsional frequency $\omega_{9 b}$ are obtained by varying the torsional stiffness of the isolation system, assuming that the mass distribution of the structure remains constant. At the same time, for a given number of isolators with built-in springs having a fixed resultant stiffness $K_{b}$ and a lateral base period $T_{b}$, the torsional stiffness $K_{\theta b}$ varies as a function of the distance of the bearings from the CM. Such variations are used in the following study.

The nonlinear lateral-torsional response of a sliding base-isolated structure-with a given location, number, coefficient of friction, and stiffness of bearings-depends mainly on the parameters $T_{s}, T_{b}, \Omega_{\theta s}, \Omega_{\theta b}$, the normalized superstructure stiffness eccentricity, $e_{s} / r$, and on the normalized strength eccentricity, $e_{b} / r$, of the isolation system. The important parameters just mentioned characterize best the nonlinear lateral-torsional response and allow for a meaningful evaluation of the influence of system parameters on the torsional coupling. Hence the range of these parameters was carefully selected in order to obtain a better understanding of the influence of the system parameters on torsional coupling and also to cover a wide spectrum of sliding isolated structures. In addition, realistic types of structural systems and sliding bearings, in various configurations, representing actual structures were designed. The study of the selected systems and the influence of system parameters are presented in the following sections.

\section{Structural System for Parametric Study}

Structural systems, consisting of several parallel frames with and without eccentric stiffness distribution are considered [see Fig. 1(a)]. The CM, the $\mathrm{CS}$, and the GC of the floors are coincident for the symmetric systems considered and are not coincident for the asymmetric systems considered. Teflon sliding bearings [shown in Fig. 1(b)] with springs are used in the sliding isolation system. The springs, built-in to the sliding bearing, are not shown in Fig. 1 $(b)$ for clarity of the figure. Five structural configurations with two isolation variations are considered. The five structural configurations include 10-, eight-, five-, two-, and one-story 3-D-shear building systems. The two sliding isolation systems considered are: (1) A system with 36 sliding bearings with springs; and (2) a system with four sliding bearings with springs. The damping ratio is considered to be $2 \%$ in the first three modes, and $5 \%$ in all the higher modes of the superstructure. A more complete description of the five structural configurations can be found in Nagarajaiah et al. (1992).

The design of the isolation system is based on a ground motion with characteristics of the ATC $0.4 \mathrm{~g} \mathrm{~S} 2$ spectrum. A maximum lateral force of $20 \%$ of the weight $W$, at the isolation interface, serves as the design criterion. The diameter of the Teflon disc considered in each sliding bearing is 313.94 $\mathrm{mm}\left(12.36 \mathrm{in}\right.$.) with a bearing pressure of $6.9 \mathrm{~N} / \mathrm{mm}^{2}(1,000 \mathrm{psi})$, and the friction characteristics as defined in (3) are $f_{\max }=0.1193, \Delta f=0.0927$, and $a=0.0236 \mathrm{sec} / \mathrm{mm}(0.6 \mathrm{sec} / \mathrm{in}$.). The linear springs are designed to provide a base period of $T_{b}=3 \mathrm{~s}$, so that the sliding isolation system has a weak recentering force. This choice of $T_{b}$ is based on the study by the writers (Nagarajaiah et al. 1992), who concluded that the base period $T_{b}$, 
has no significant influence on the torsional coupling of sliding isolated structures with weak recentering force $\left(T_{b}>2-3 \mathrm{~s}\right)$ for a wide range of the earthquake ground motions. Sliding systems with weak recentering force develop frictional forces that are nearly two times the force developed by the spring sytem. In such cases the springs perform only the function of recentering the system and do not alter the frequency content of the structure (Constantinou et al. 1991).

The total weight $(W)$ or mass of the structure is kept constant in all cases. A variable mass offset is achieved by assuming that a portion of the mass is eccentric in the $y$-direction, hence both mass moment of inertia and the radius of gyration $(r)$ varies. The mass remains symmetric about the $y$-axis. The friction parameters of the sliding bearings defined by (3), are adjusted based on experimental results (Constantinou et al. 1990) to account for the changes in bearing pressure due to the mass offset, from which the strength eccentricity, $e_{b}$, of the isolation system is computed. Three positions of the eccentric mass are selected leading to mass offsets [see Fig. 1(a)] $o_{m} / L=$ $0.0,0.083$, and 0.210 . The corresponding radii of gyration at all floors and at the base are $r / L=0.408,0.400$, and 0.422 . The corresponding normalized strength eccentricity for the two sliding isolation systems are $e_{b} / r=0,0.05$, and 0.106 . Identical superstructure eccentricities, $e_{s}$, are employed in both $x$ - and $y$-directions [see Fig. $1(a)]$ unless mentioned. In the following parametric study the superstructure eccentricity is varied from $\dot{e}_{s} / r=0$ (no eccentricity) to $e_{s} / r=0.5$ (which is $21 \%$ of the length $L$ of the floor plan).

\section{Ground Motions for Parametric Study}

Several typical earthquakes were used in this study, however, results of only two types of earthquakes are presented. Their selection was made to cover two extreme cases of frequency content. The first type consists of a moderately high-frequency content $1940 \mathrm{El}$ Centro earthquake (S00E in $x$ direction and S90W in $y$-direction) with peak ground acceleration (PGA) of $0.34 \mathrm{~g}$. The second type consists of a predominantly low-frequency content 1985 Mexico City earthquake (N90W in $x$-direction and SOOE in $y$-direction) with PGA of $0.17 \mathrm{~g}$.

\section{Effect of Number of Bearings}

The importance of the isolation system composition is determined first. The two configurations described of 36 and four bearings supporting a 3D-shear building structural system, with identical system parameters, provide a lower and an upper limit for a realistic assessment. For the system with four sliding bearings the total mass is scaled by a factor of nine so that bearings and bearing pressures identical to the 36 bearing system result. The 3-D-shear building structural systems considered are 10, eight, five, and two stories tall. Identical floor masses are chosen such that the total mass of the floors is four times the mass of the base.

In addition, a series of single-story 3-D-shear buildings are selected with periods identical to the first three modes of the multistory configurations, just mentioned, and with a floor mass equal to the total floor mass of the superstructure they represent. The system configurations considered also allow for a simultaneous investigation of the contribution of higher modes of vibration to the response of sliding isolated structures.

Three combinations of structure-isolation systems, with ratio $L / b=1$, are considered in the parametric study: (1) Multistory structures with iso- 
lation system of 36 bearings (36 BMS); (2) single-story structures with isolation system of 36 bearings (36 BSS); (3) single-story structures with isolation system of four bearings (4 BSS). The value of parameters $T_{b}, e_{s} / r$, $e_{b} / r, \Omega_{\theta s}$, and $\Omega_{\theta b}$ are considered to be the same in all the systems. The mass of the structure is considered to be symmetric, hence the isolation eccentricity $e_{b} / r=0\left(o_{m} / L=0\right)$. The fundamental periods $T_{s}$ of the selected structures (i.e., preisolation periods) are $0.3 \mathrm{~s}, 0.6 \mathrm{~s}, 0.9 \mathrm{~s}$, and $1.2 \mathrm{~s}$ for the two-, five-, eight-, and 10-storied structures, respectively. The torsional to lateral frequency ratio of the superstructure, $\Omega_{\theta s}$, is selected as 1.0 , to increase the chance for strong torsional coupling. The same ratio for the base, $\Omega_{\theta b}$, is selected to be 1.7 . This is obtained in the case with 36 bearings, by placing the bearings such that the corner distance, $a$, from the $\mathrm{CM}$ along the $x$ - or $y$-axis fulfills the ratio $a / r=1.56$. The same condition is fulfilled in the four bearing system with a ratio $a / r=1.23$. Influence of several ground motions were studied, the $1940 \mathrm{El}$ Centro earthquake excitation produced the maximum differences in the response of different systems just described. The results for this case are presented next.

The results for varying superstructure period $T_{s}$ and eccentricity $e_{s} / r=$ 0.25 are shown in Fig. 3. The peak response values at the CM are presented in Fig. 3. The peak response quantities presented are: (1) The structural shears $F_{x s}, F_{y s}$ and the torque $T_{s}$ at the first-story level above the base; (2) the displacements $U_{x s}, U_{y s}$ and the rotation $U_{\theta s}$ of the top floor, relative to the base; and (3) the displacements $U_{x b}, U_{y b}$ and the rotation $U_{\theta b}$ of the base, relative to the ground. The aforementioned peak values are normalized with respect to either the peak ground displacement $U_{\text {go }}[108.96 \mathrm{~mm}$ (4.29 in.); for El Centro SOOE component] or the total weight $W$ and length $L$. The aforementioned response quantities characterize best the influence of torsional coupling due to strong ground motions in presence of biaxial interaction in the isolators.

The analysis results, shown in Fig. 3, show that the single-story structure with either four or 36 isolators (i.e., 4BSS or 36BSS) respond almost identically in both translation and rotation. The response quantities shown in Fig. 3 were obtained for superstructures with constant stiffness eccentricity $e_{s} / r=0.25$. If the superstructure eccentricity is varied from a symmetric case to asymmetric case of $e_{s} / r=0.5$, with a constant superstructure period $T_{s}=1.2 \mathrm{~s}$, the same effect as just described is observed (see Fig. 4) for the case of 4BSS and 36BSS. It can therefore be concluded that the number of bearings do not affect the torsional and lateral response for a given set of structural parameters $T_{s}, T_{b}, \Omega_{\theta s}, \Omega_{\theta b}, e_{s} / r, e_{b} / r, r / L$, and $L / b$.

\section{Effect of Higher Modes}

Same analysis just described is used to emphasize the difference between the multistory structure analysis and single-story structure analysis. Since the analysis is done by direct integration of the equations of motions, the response obtained in Figs. 3 and 4 for multistoried structures (case 36 BMS) includes implicitly the influence of higher modes of vibrations. Comparing their response with those of single-story structure (case 36BSS), it can be observed that differences appear at the larger periods (see Fig. 3). However, these differences remain smaller than $10 \%$ of the actual response of multistoried structures. Since this difference is not of great importance, further studies of significant parameters will be done on equivalent single-story systems. 


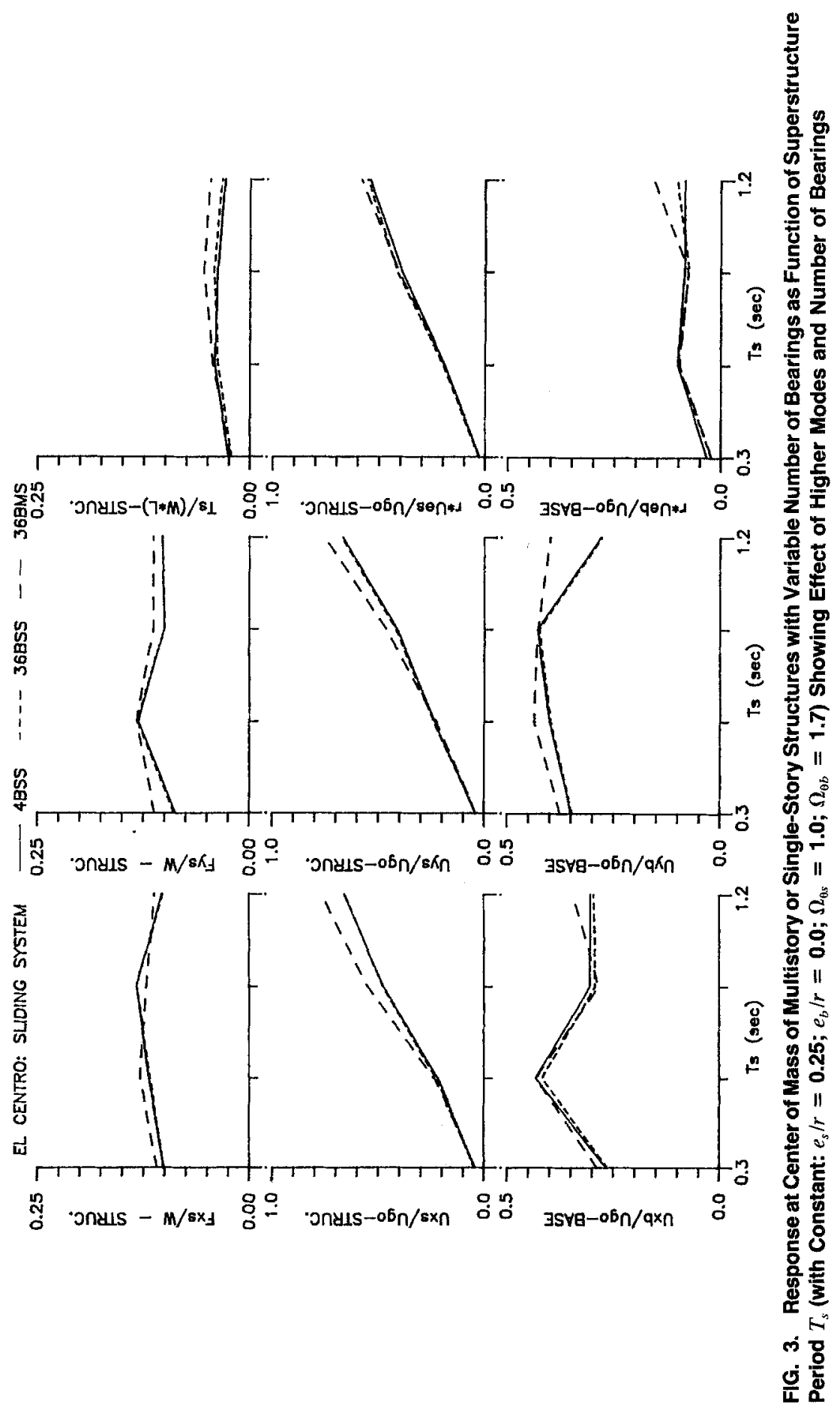




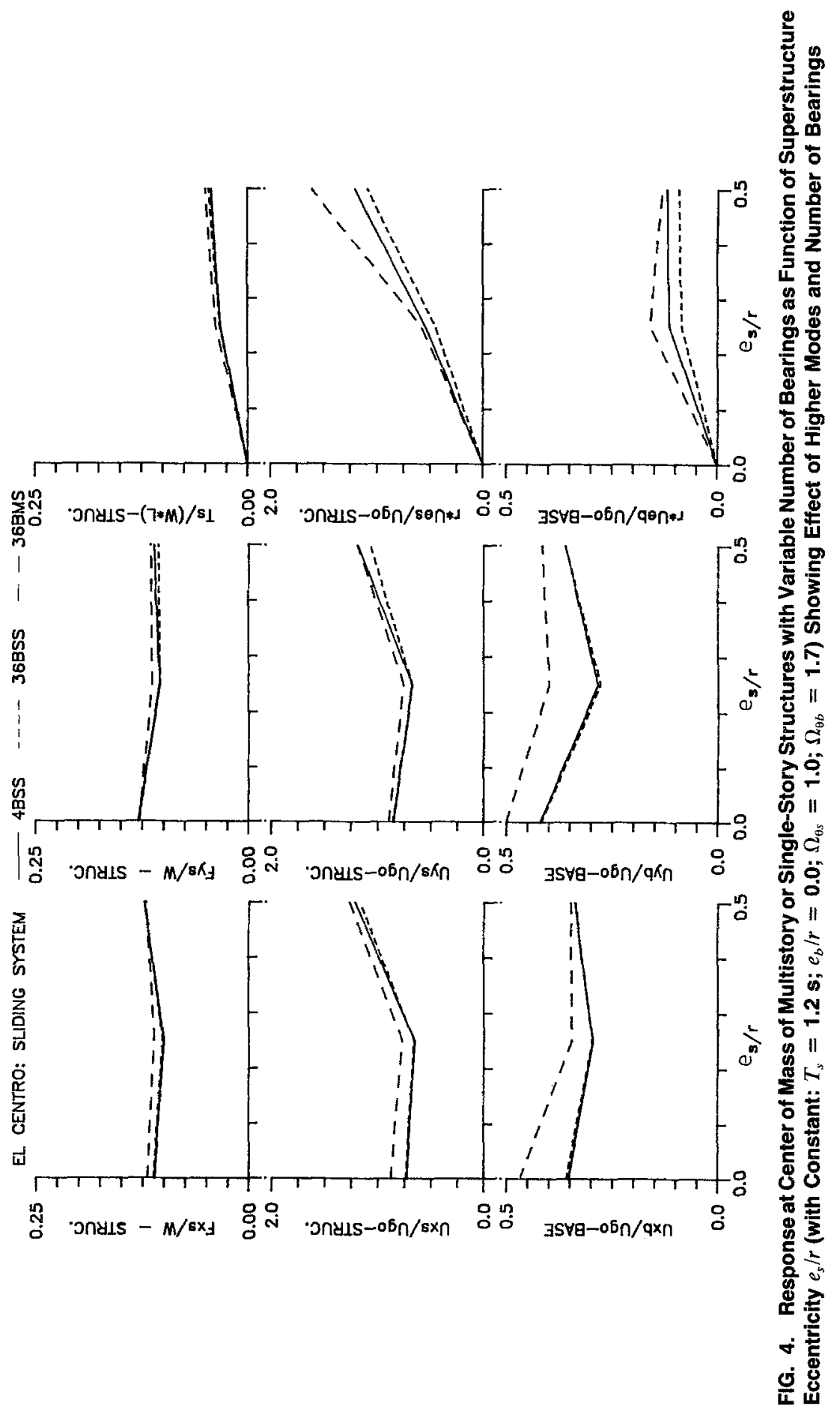




\section{Effect of Superstructure FleXibiLity}

The influence of the superstructure period, $T_{s}$, on the coupled lateraltorsional response is evaluated in this section using a variety of parameters. The most relevant ones are the superstructure frequency ratio, $\Omega_{\theta s}=0.8$, $1.0,1.7$, the base frequency ratio, $\Omega_{\theta b}=1.2,1.7$, the biaxial superstructure eccentricity, $e_{s} / r=0.25$, the uniaxial isolation eccentricity $e_{b} / r=0.05\left(o_{m} /\right.$ $L=8.3 \%$ ), base period $T_{b}=3.0 \mathrm{~s}$, ratio $L / b=1$, and $a / r=1.46$. The superstructure period $T_{s}$ (i.e., preisolation period) is varied over the range 0.3 and $1.2 \mathrm{~s}$ (or $1.6 \mathrm{~s}$ ). The influence of the aforementioned parameters for the two typical ground motions are shown in Table 1. Further results are shown in Figs. 5 and 6.

Table $1(a)$ presents results such as $\bar{U}_{c b}$, the ratio of peak corner base displacement to the peak base displacement at the $\mathrm{CM}$, and $\bar{U}_{c s}$, the ratio of peak corner structure displacement (relative to base) to the peak structure displacement at the CM (relative base). Furthermore, the values of factor $T_{\text {amp }}$, the dynamic torque amplification factor, are presented. The factor $T_{\text {amp }}$ is defined as the ratio of the dynamic torque to the static torque at the CS of the superstructure (Lee 1980). The static torque used for the computation of the factor $T_{\text {amp }}$ is the square root sum of squares (SRSS) of the

TABLE 1. Torsional Amplification: Effect of Superstructure Flexibility (Constant: $\left.T_{b}=3.0 \mathrm{~s} ; e_{s} / r=0.25 ; e_{b} / r=0 / 05 ; L / b=1 ; a / r=1.46\right)$

\begin{tabular}{|c|c|c|c|c|c|c|c|c|c|c|}
\hline \multirow{2}{*}{$\begin{array}{c}\text { Period } \\
T_{s}(\mathrm{~s}) \\
\text { (1) }\end{array}$} & \multirow[b]{2}{*}{$\begin{array}{c}\Omega_{\theta b} \\
(2)\end{array}$} & \multicolumn{3}{|c|}{$\Omega_{\partial s}=1.7$} & \multicolumn{3}{|c|}{$\Omega_{\theta s}=1.0$} & \multicolumn{3}{|c|}{$\Omega_{\theta s}=0.8$} \\
\hline & & $\begin{array}{l}\tilde{U}_{c b} \\
\text { (3) }\end{array}$ & $\begin{array}{l}\bar{U}_{c s} \\
\text { (4) }\end{array}$ & $\begin{array}{c}T_{\text {amp }} \\
\text { (5) }\end{array}$ & $\begin{array}{l}\bar{U}_{c b} \\
(6)\end{array}$ & $\begin{array}{l}\bar{U}_{c s} \\
(7)\end{array}$ & $\begin{array}{c}T_{\text {amp }} \\
\text { (8) }\end{array}$ & $\begin{array}{l}\bar{U}_{c b} \\
(9)\end{array}$ & $\begin{array}{c}\bar{U}_{c s} \\
(10)\end{array}$ & $\begin{array}{l}T_{\text {amp }} \\
\text { (11) }\end{array}$ \\
\hline \multicolumn{11}{|c|}{ (a) El Centro } \\
\hline 0.3 & 1.7 & 1.07 & 1.22 & 1.77 & 1.13 & 1.68 & 2.04 & 1.10 & 2.14 & 1.85 \\
\hline 0.3 & 1.2 & 1.08 & 1.20 & 1.74 & 1.17 & 1.73 & 1.99 & 1.21 & 1.93 & 1.89 \\
\hline 0.3 & Fixed base & - & 1.21 & 1.52 & - & 1.72 & 1.99 & - & 2.51 & 1.96 \\
\hline 0.6 & 1.7 & 1.13 & 1.23 & 1.68 & 1.28 & 2.19 & 2.31 & 1.10 & 1.95 & 1.77 \\
\hline 0.6 & 1.2 & 1.20 & 1.23 & 1.64 & 1.30 & 2.04 & 2.19 & 1.19 & 1.96 & 1.49 \\
\hline 0.6 & Fixed base & - & 1.28 & 1.86 & - & 2.48 & 3.54 & 一 & 2.23 & 1.75 \\
\hline 0.9 & 1.7 & 1.07 & 1.46 & 2.73 & 1.06 & 1.99 & 2.37 & 1.30 & 2.19 & 1.43 \\
\hline 0.9 & 1.2 & 1.17 & 1.38 & 2.38 & 1.22 & 1.78 & 2.04 & 1.67 & 2.03 & 1.31 \\
\hline 0.9 & Fixed base & - & 1.27 & 2.12 & - & 2.33 & 2.42 & - & 1.61 & 1.92 \\
\hline 1.2 & 1.7 & 1.28 & 1.26 & 2.11 & 1.22 & 1.74 & 2.04 & 1.19 & 2.05 & 1.59 \\
\hline 1.2 & 1.2 & 1.48 & 1.35 & 1.94 & 1.57 & 1.58 & 1.93 & 1.33 & 1.78 & 1.49 \\
\hline 1.2 & Fixed base & - & 1.25 & 2.15 & - & 1.45 & 1.89 & - & 1.63 & 1.19 \\
\hline \multicolumn{11}{|c|}{ (b) Mexico City } \\
\hline 0.6 & 1.7 & 1.08 & 1.10 & 0.86 & 1.08 & 1.23 & 1.42 & 1.08 & 1.39 & 0.91 \\
\hline 0.6 & Fixed base & - & 1.08 & 1.22 & - & 2.42 & 3.20 & - & 1.90 & 1.33 \\
\hline 0.9 & 1.7 & 1.10 & 1.09 & 0.77 & 1.11 & 1.18 & 1.00 & 1.11 & 1.29 & 1.14 \\
\hline 0.9 & Fixed base & - & 1.13 & 1.25 & - & 1.75 & 1.73 & - & 1.87 & 1.37 \\
\hline 1.2 & 1.7 & 1.09 & 1.16 & 1.11 & 1.10 & 1.44 & 1.69 & 1.13 & 2.34 & 2.46 \\
\hline 1.2 & Fixed base & - & 1.10 & 1.12 & - & 1.82 & 2.06 & - & 2.22 & 2.11 \\
\hline 1.6 & 1.7 & 1.10 & 1.12 & 1.10 & 1.02 & 1.72 & 2.68 & 1.25 & 2.20 & 2.06 \\
\hline 1.6 & Fixed base & - & 1.07 & 1.10 & - & 2.11 & 2.82 & - & 2.13 & 1.93 \\
\hline
\end{tabular}

Notes: $\bar{U}_{c b}=$ peak corner base displacement/peak base displacement at $\mathrm{CM} ; \bar{U}_{c s}=$ peak corner structure displacement/peak structure displacement at $\mathrm{CM} ; T_{\text {amp }}=$ dynamic torque/static torque, at CS of superstructure. 


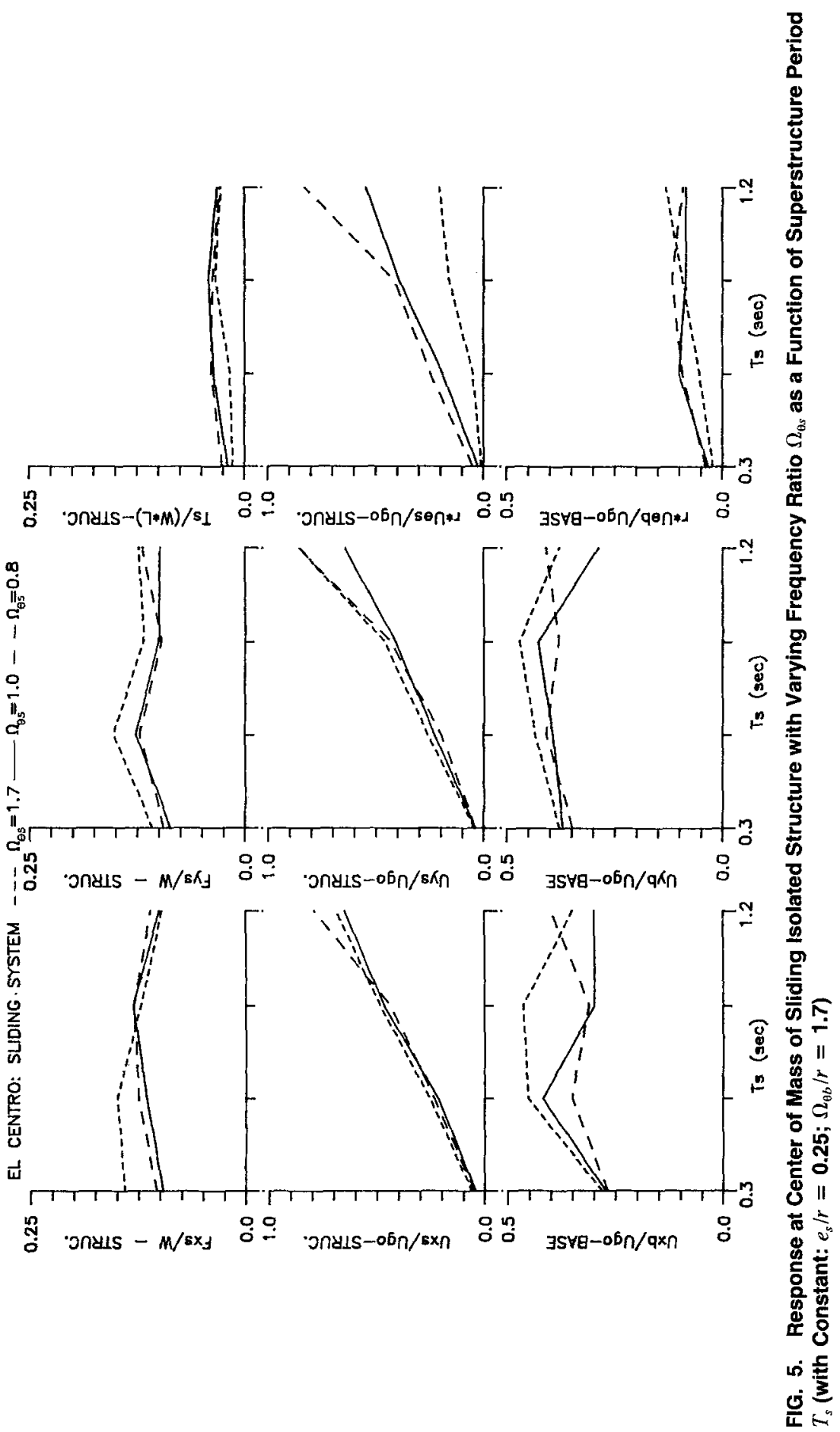



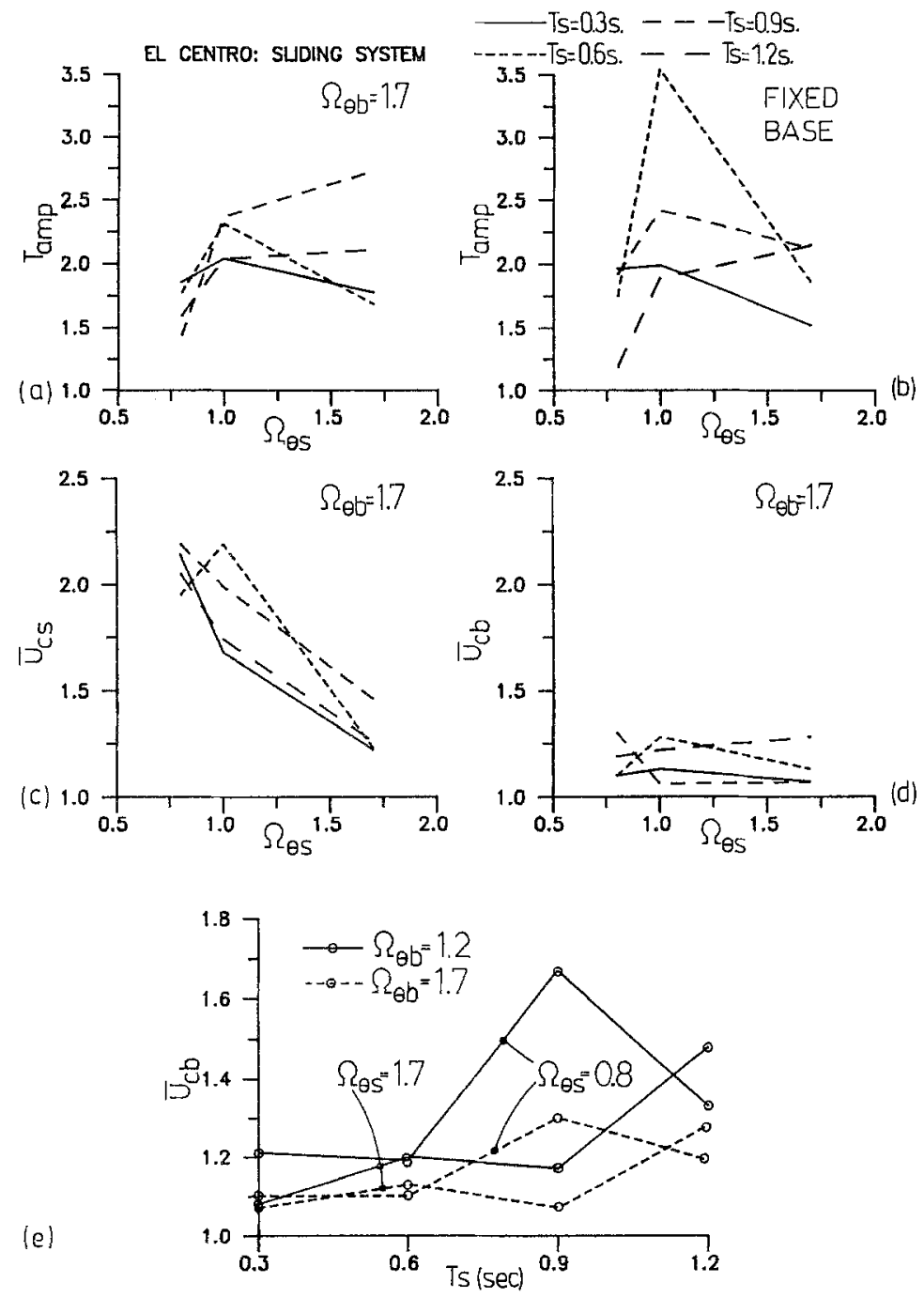

FIG. 6. Dynamic Torque Amplification and Corner Displacement Magnification as Function of Frequency Ratio $\Omega_{\theta s}$ and Superstructure Period $T_{s}$ (with Constant: $e_{s} / r=0.25 ; e_{b} / r=0.05$ )

torques $F_{x s} e_{s}$ and $F_{y s} e_{s}$, where $F_{x s}$ and $F_{y s}$ are the peak structural shear forces obtained in the dynamic analysis. The magnitude of factor $T_{\text {amp }}$ is an indication of the extent of torsional coupling, hence if $T_{\text {amp }}$ is close to unity then the torsional coupling is small.

It is evident from Fig. 5 that the peak structural shears and torque are virtually unaffected by the period $T_{s}$. Hence the peak relative structural displacement and rotation increase with increasing period $T_{s}$. At the same time in Fig. 5 the torsional response is influenced by the superstructure torsional to lateral frequency ratio, $\Omega_{\theta s}$.

The dynamic torque amplification factor, $T_{\text {amp }}$, of the sliding isolated 
structure shown in Fig. $6(a)$ has the same order of magnitude as that of the nonisolated structure shown in Fig. $6(b)$; however, no clear trend of the influence of period $T_{s}$ is evident. The order of magnitude of the amplification factor $T_{\text {amp }}$ indicates that sliding isolated structures amplify the "static torque" no less than the nonisolated structures. However, the structure shear and torque generated in the sliding isolated structure is one order of magnitude less than that of the elastic fixed base structure (Nagarajaiah et al. 1992).

The translational motion at the corner of the superstructure is larger than the one at the CM, as expected, since torsional coupling is involved. The corner displacement magnification $\bar{U}_{c s}$ is a function of the superstructure torsional to lateral frequency ratio $\Omega_{\theta s}$ as shown in Fig. $6(c)$, and again no clear trend of the influence of period $T_{s}$ is evident. The larger the ratio $\Omega_{0 s}$, the smaller the torsional response. However, for smaller frequency ratio $\Omega_{\theta s}$ the corner displacement magnification $\bar{U}_{c s}$ indicates a demand on the corner frames of two to three times the demand on the frames near the CM.

The torsional properties of the sliding isolation system are dictated by the frequency ratio, $\Omega_{\theta b}$. With the decrease in the frequency ratio of the base, $\Omega_{\theta b}$, the corner base displacement amplification, $\bar{U}_{c b}$, increases and also the ratio $\bar{U}_{c b}$ generally increases with increasing superstructure period $T_{s}$ [this trend is evident in Fig. 6(e) in which the results for frequency ratio $\Omega_{\theta s}=1.0$ are omitted for clarity of the figure]. The ratio $\bar{U}_{c b}$ is not distinctly affected by the superstructure frequency ratio $\Omega_{\theta s}$ [see Figs. $6(d)$ and $6(e)$ ].

Therefore, the flexibility of the superstructure leads to amplification or reduction of torsional effects depending on the torsional characteristics: (1) The superstructure frequency ratio, $\Omega_{\theta s}$; and (2) the base frequency ratio, $\Omega_{\theta b}$. More detailed values that support the aforementioned discussion can be seen in Table 1 for both typical earthquake motions.

\section{EfFEct OF SUPERSTRUCTURE ECCENTRICITY}

The superstructure stiffness eccentricity, $e_{s} / r$, is the most important parameter that causes torsional coupling and torsional motions. The effect of eccentricity, $e_{s} / r$, in the presence of a variety of system parameters is examined in this section. The biaxial superstructure eccentricity is varied between the symmetric case, $e_{s} / r=0$, and the asymmetric case, $e_{s} / r=0.5$ $\left(e_{s}=0.21 L\right)$, in a structure with superstructure period $T_{s}=1.2 \mathrm{~s}$, in the presence of superstructure frequency ratio, $\Omega_{\theta s}=0.8,1.0,1.7$, base frequency ratio, $\Omega_{\theta b}=1.2,1.7,2.0$, and base period $T_{b}=3.0 \mathrm{~s}$, isolation eccentricity $e_{b} / r=0$, ratio $L / b=1$, and $a / r=1.23$. The influence of the aforementioned parameters for several typical ground motions were studied and the complete set of results can be found in Nagarajaiah et al. (1992). Only the important results for one of the earthquakes is presented herein. The results for the case of El Centro excitation and for constant frequency ratios $\Omega_{\theta s}=1.0$ and $\Omega_{\theta b}=1.7$ are shown in Fig. 4 . The important trends to note in Fig. 4 are that the torsional response in the superstructure and the base increases with increasing eccentricity $e_{s} / r$ and also that the lateral displacement at the $\mathrm{CM}$ increases, instead of decreasing as in an elastic system, with increasing eccentricity $e_{s} / r$.

Further results for the case of El Centro excitation are presented in Fig. 7. As evident from Figs. 7(a) and 7(c) [the results for frequency ratio $\Omega_{\theta s}$ $=1.0$ in Figs. $7(a)$ and $7(b)$ are omitted for clarity of the figures] the corner displacement magnification in the superstructure, $\bar{U}_{c s}$, increases with increasing eccentricity $e_{s} / r$ and also increases with decreasing superstructure 

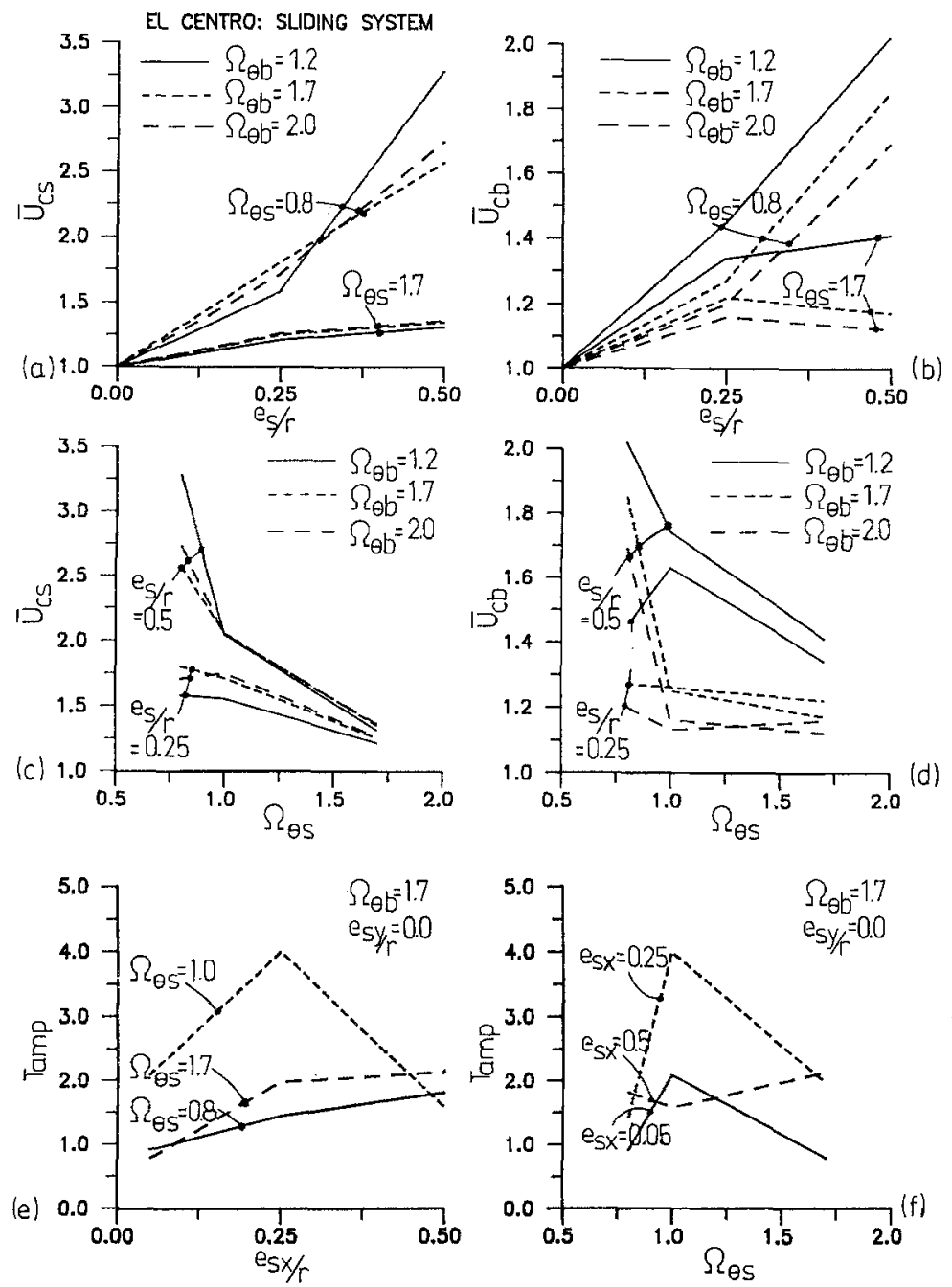

FIG. 7. Corner Displacement Magnification and Dynamic Torque Amplification as Function of Superstructure Eccentricity $e_{s} / r$ and Frequency Ratio $\Omega_{0 s}$ (with Constant: $T_{s}=1.2 \mathrm{~s} ; e_{b} / r=0.0$ )

and base frequency ratios, $\Omega_{\mathrm{\theta s}}$ and $\Omega_{\mathrm{e} b}$. A similar trend in the corner displacement magnification at the base, $U_{c b}$, can be observed in Figs. $7(b)$ and $7(d)$.

Next, to examine the effect of uniaxial superstructure eccentricity, the eccentricity $e_{s} / r$ is made zero in the $y$-direction $\left(e_{s y} / r=0.0\right)$ and is varied from 0.05 to 0.5 in the $x$-direction $\left(e_{s x} / r=0.05-0.5\right)$. All the other parameters just described are kept the same. The dynamic torque amplification factor $T_{\mathrm{amp}}$ shown in Figs. $7(e)$ and $7(f)$, is significant and occurs at eccentricity $e_{s x} / r=0.25$ and not at smaller values of $e_{s x} / r$, such as $e_{s x} / r=0.05$, as in elastic structures. However, the maximum amplification, $T_{\text {amp }}$, occurs at $\Omega_{\theta s}=1.0$ as in elastic structures. 
Therefore, increasing superstructure eccentricity leads to amplification of torsional response; however, this amplification diminishes with increasing superstructure and base torsional to lateral frequency ratio, $\Omega_{\theta s}$ and $\Omega_{\theta b}$. The maximum torque amplification, $T_{\text {amp }}$, occurs at $\Omega_{\theta s}=1.0$ as in elastic structures; however, it does not attain its peak value for small eccentricities as in elastic structures.

\section{EFFECt OF IsOLATION SySTEM ECCENTRICITY}

Previous studies (Zayas et al. 1987, 1989) have shown that eccentricity in the sliding isolation system causes negligible torsional response. This fact was further verified in this study by varying the isolation system eccentricity $e_{b} / r=0.0,0.05,0.106$ (and the corresponding mass offsets $o_{m} / L=0,0.083$, 0.21 ). The results (Nagarajaiah et al. 1992), not presented here because of space limitations, showed that the strength eccentricity, $e_{b} / r$, in the isolation system produces negligible torsional response. Moreover, the negligible torsional response in sliding isolated structures with mass offset, in the absence of superstructure eccentricity, is because of the development of bearing forces proportional to the vertical weight distribution with their resultant being at the $\mathrm{CM}$ of the base, with no eccentricity in the isolation system.

An investigation of the effect of plan dimensions with $L / b=4$, with plan area $L \times b$ kept the same as in the case with $L / b=1$, showed [the results can be found in Nagarajaiah et al. (1992)] that the variation of plan dimensions did not alter the torsional response and was virtually similar to the case $L / b=1$.

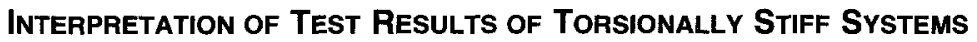

Zayas et al. (1987) tested a one-fourth-scale steel structure, 2,743-mm (108 in.) long and 1,829-mm (72-in.) wide, on sliding isolation system. The model weighted $80.06 \mathrm{kN}$ (18 kips), with $48.93 \mathrm{kN}$ (11 kips) of superstructure weight and $31.14 \mathrm{kN}$ (7 kips) of base weight. The sliding isolation system was made of four sliders sliding on smooth spherical concave surface. The rising pendulum action of the slider along the polished spherical surface yielded the recentering force. the corresponding prototype system parameters were: $T_{s}=0.32 \mathrm{~s}, T_{b}=2 \mathrm{~s}, \Omega_{\theta s}=1.8, e_{s} / L=0.38, o_{m} / L=0.15$, $r / L=0.33, L / b=1.5$, and $a / r=1.5$. The measured coefficient of sliding friction $f_{\max }=0.08$. Zayas et al. (1987) reported corner displacement magnifications, $\bar{U}_{c b}=1.04$ and $\bar{U}_{c s}=1.06$, under $1940 \mathrm{El}$ Centro NS excitation. The low values of corner displacement magnification at the base, $\vec{U}_{c b}$, is because the low period of the superstructure $T_{s}=0.32 \mathrm{~s}$, and the highfrequency ratios, $\Omega_{\theta s}=2.2$ and $\Omega_{\theta b}=1.8$ (in section $a$ of Table $1 \bar{U}_{c b}=$ 1.07 for $T_{s}=0.3 \mathrm{~s} ; \Omega_{\theta s}=1.7 ; \Omega_{\theta b}=1.7$ ). The main reason for the very low values of corner displacement magnification in the superstructure, $\bar{U}_{c s}$, is because of the high-frequency ratio $\Omega_{\theta s}=2.2$. From Fig. $6(c)$ we find that the value of $\bar{U}_{c s}$ decreases with increasing frequency ratio $\Omega_{\theta s}$, and for $\Omega_{\theta s}=2.2$ and $e_{s} / r=0.5$ the approximate magnification ratio $\tilde{U}_{c s} \cong 1$. Hence as discussed in the introduction, the conclusion of the studies by Zayas et al. (1987, 1989), that torsional response is negligible in sliding isolated structures, is applicable to torsionally stiff sliding isolated structures only. 


\section{Conclusions}

The objective of this study was to identify the key parameters that influence the torsional coupling in sliding isolated structures. The important system parameters identified and the trends of structural response presented for the two earthquakes apply in general. The main conclusions of the study are as follows.

1. The torsional coupling in sliding isolated structures is important as the dynamic torque amplification in the superstructure, $T_{\text {anp }}$, has in many cases the same order of magnitude as that of the nonisolated structure. However, the structure shear and torque generated in the sliding isolated structure is one order of magnitude less than that of the elastic fixed-base structure.

2. The superstructure flexibility, $T_{s}$, leads to amplification or reduction of the torsional response depending on the torsional characteristics: (1) Superstructure torsional to lateral frequency ratio $\Omega_{\theta s}$; and (2) base torsional to lateral frequency ratio, $\Omega_{\theta b}$.

3. The main source of torsional motions in sliding isolated structures is the superstructure stiffness eccentricity $e_{s} / r$. Increasing the superstructure eccentricity leads to amplification of the torsional response. However, this amplification diminishes with increasing superstructure and base torsional to lateral frequency ratios, $\Omega_{\theta s}$ and $\Omega_{\theta b}$. The torque amplification, $T_{\text {amp }}$, attains its peak value at large eccentricities, instead of small eccentricities $\left(e_{s} / r=0.05\right)$ as in elastic structures.

4. Strength eccentricity in the sliding isolation system produces negligible torsional response, provided no stiffness eccentricity exists in the superstructure.

5. The superstructure and base torsional to lateral frequency ratios $\Omega_{\theta s}$ and $\Omega_{\theta b}$, respectively, have a significant influence on the torsional response. The maximum torque amplification occurs at frequency ratio $\Omega_{\theta s}=1.0$. The corner displacement magnification, $\bar{U}_{c s}$ and $\bar{U}_{c b}$, generally increases with decreasing frequency ratios $\Omega_{\theta s}$ and $\Omega_{\theta b}$. The torsional response is small or negligible, and no torque amplification occurs, for torsionally stiff systems $\left(\Omega_{\theta s}\right.$ and $\left.\Omega_{\theta b} \geq 2.0\right)$.

6. The number of bearings in a sliding isolated structure has very little influence on the response, given a set of parameters $T_{s}, T_{b}, \Omega_{\theta s}, \Omega_{\theta b}, e_{s} / r$, $e_{b} / r, r / L$, and $L / b$.

7. The higher mode effects on the lateral-torsional response of sliding isolated structures is important in systems with flexible superstructures.

\section{ACKNOWLEDGMENTS}

The financial support by the National Center for Earthquake Engineering Research grant 90-2102B (NSF grant ECE 86-07591) for this work is acknowledged.

\section{Appendix. References}

Buckle, I. G., and Mayes, R. L. (1990). "Seismic isolation: History, application, and performance-World overview." Earthquake Spectra, 6(2), 161-202.

Campbell, T. I., Pucchio, C. B., Roeder, C. W., and Stanton, J. F. (1991). "Frictional characteristics of PTFE used in slide surfaces of bridge bearings." Proc. 3rd World Conf. on Bearings for Concrete Structures, American Concrete Institute, 847-870. 
Constantinou, M. C., Mokha, A., and Reinhorn, A. M. (1990). "Teflon bearings in base isolation II: Modeling." J. Struct. Engrg., ASCE, 116(2), 455-474.

Constantinou, M. C., Mokha, A., and Reinhorn, A. M. (1991). "Study of sliding bearing and helical-steel-spring isolation system." J. Struct. Engrg., ASCE, 117(4), 1251-1275.

Eisenberger, M., and Rutenberg, A. (1986). "Seismic isolation of asymmetric shear buildings." Engrg. Struct., 8(1), 2-8.

Goel, R. K., and Chopra, A. K. (1990). "Inelastic seismic response of one-storey asymmetric plan systems: Effects of stiffness and strength distribution." Earthquake Engrg. Struct. Dyn., 19(3), 949-970.

Hart, G. C., Dijulio, R. M., and Lew, M. (1975). "Torsional response of high rise buildings." J. Struct. Div., ASCE, 101(2), 397-416.

Hisano, M., et al. (1988). "Study of sliding isolation system: Triaxial shaking table test and its simulation." Proc. Ninth World Conf. on Earthquake Engrg., Japan Association for Earthquake Disaster Prevention, V, 741-746.

Lee, D. M. (1980). "Base isolation for torsion reduction in asymmetric structures under earthquake loading." Earthquake Eng. Struct. Dyn., 8(3), 349-359.

Mokha, A., Constantinou, M. C., and Reinhorn, A. M. (1993). "Verification of friction model of Teflon bearings under triaxial load." J. Struct. Engr., ASCE, 119(1).

Mostaghel, N., and Khodaverdian, M. (1988). "Seismic response of structures supported on R-FBI system." Earthquake Eng. Struct. Dyn., 16(6), 839-854.

Nagarajaiah, S., Reinhorn, A. M., and Constantinou, M. C. (1990). "Analytical modeling of three dimensional behavior of base isolation devices." Proc. Fourth U.S. Nat. Conf. on Earthquake Engrg., Earthquake Engrg. Res. Inst., 3, 579 588.

Nagarajaiah, S., Reinhorn, A. M., and Constantinou, M. C. (1991a). "3D-BASIS: Nonlinear dynamic analysis of 3D-base isolated structures PART-II." Report No. NCEER-91-0005, Nat. Ctr. for Earthquake Engrg. Res., Buffalo, N.Y.

Nagarajaiah, S., Reinhorn, A. M., and Constantinou, M. C. (1991b). "Nonlinear dynamic analysis of 3D-base isolated structures." J. Struct. Engrg., ASCE, 117(7), 2035-2054.

Najarajaiah, S., Reinhorn, A. M., and Constantinou, M. C. (1992). "Lateral torsional response of base isolated structures: Sliding and elastomeric systems." $R e$ port No. NCEER-92, Nat. Ctr. for Earthquake Engrg. Res., Buffalo, N.Y.

Pan, T. C., and Kelly, J. M. (1983). "Seismic response of torsionally coupled base isolated structures." Earthquake Engrg. Struct. Dyn., 11(6), 749-770.

Park, Y. J., Wen, Y. K., and Ang, A. H. S. (1986). "Random vibration of hysteretic systems under bidirectional ground motions." Earthquake Eng. Struct. Dyn., 14(4), 543-557.

Pekau, O. A., and Guimond, R. (1991). "Controlling seismic response of eccentric structures by friction dampers." Earthquake Eng. Struct. Dyn., 20(6), 505-522.

Reinhorn, A. (1980). "Discussion on paper by Dempsey, K. M. and Irvine, H. M." Earthquake Eng. Struct. Dyn., 8(1), 75-77.

Reinhorn, A. M., Rutenberg, A., and Gluck, J. (1977). "Dynamic torsional coupling in asymmetric building structures." Building Environ., 12(4), 251-261.

Sadek, A. W., and Tso, W. K. (1988). "Strength eccentricity concept for inelastic analysis of symmetric structures." Proc. Ninth World Conf. on Earthquake Engrg., Japan Association for Earthquake Disaster Prevention, V, 91-96.

Su, L., Ahmadi, G., and Tadjbakhsh, I. G. (1989). "A comparative study of performance of various base isolation systems, Part I: Shear beam structures." Earthquake Eng. Struct. Dyn., 18(1), 11-32.

Zayas, V., Low, S., and Mahin, S. (1987). "The FPS system: Experimental report." Report No. UCB/EERC-87-01, Earthquake Engr. Res. Ctr., Berkeley, Calif.

Zayas, V., Low, S., Bozzo, L., and Mahin, S. (1989). "Feasibility and performance studies on improving the earthquake resistance of buildings using the friction pendulum system." Report No. UCB/EERC-89-09, Earthquake Engrg. Res. Ctr., Berkeley, Calif. 